\title{
Smokeless tobacco is associated with more severe but less painful mucositis
}

\section{Dr. Sandip Mukhopadhyay, MD, NFPM Arpan Ghosh}
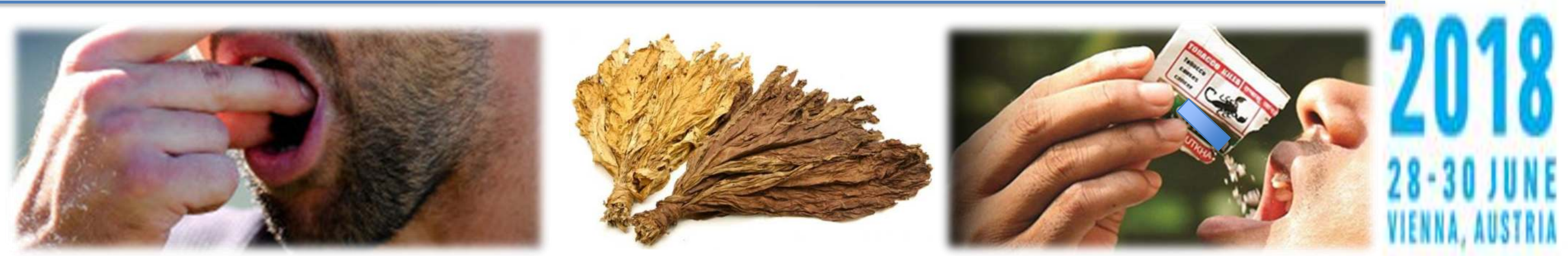

\section{Introduction:}

Head and neck cancer patients are likely to develop oral mucositis during their course of treatment with Radiation therapy or chemoradiation. Smoking - considered as a risk factor for the development of oral mucositis (OM) Smokeless tobacco- consumed in some part of the world

However, the association of smokeless tobacco use and oral mucositis (OM) was hardly ever explored.

\section{Objective:}

1. To find out any association between use of smokeless tobacco with development of $\mathrm{OM}$, in cancer patients undergoing radiation or chemotherapy.

2. To compare the development and severity of OM in such patients with smokers or nontobacco users.

\section{Materials \& methods:}

Design: Observational, cross-sectional study

Duration: 3 month

Study setting: Tertiairy care Hospital in Eastern India

Study participants: The head and neck cancer patients who developed OM during their course of radiation or chemotherapy.

Methodology:

The development, onset, severity of OM were recorded

Pain symptom in 0-10 NRS were noted among all patients

All data were compared among the subgroups of smokeless tobacco user, smokers and others

\section{Results:}

\begin{tabular}{|cccccc|}
\hline & $\begin{array}{c}\text { Smokeless } \\
\text { tobacco only } \\
(\mathrm{SL})\end{array}$ & $\begin{array}{c}\text { Smoker+ } \\
\text { smokeless } \\
(\mathrm{SS})\end{array}$ & $\begin{array}{c}\text { Only } \\
\text { Smokers (S) }\end{array}$ & None (N) & P value \\
\hline $\begin{array}{c}\text { Day of onset } \\
\text { after start of } \\
\text { RT (mean) }\end{array}$ & $5.5 \pm 1.29$ & $5.8 \pm 1.6$ & $7.9 \pm 1.26$ & $8.7 \pm 2.2$ & 0.002 \\
\hline $\begin{array}{c}\text { Severity of } \\
\text { Pain (mean } \\
\text { NRS) }\end{array}$ & $7 \pm 0.81$ & $9 \pm 0.86$ & $9 \pm 2.58$ & $9 \pm 1.7$ & 0.24 \\
\hline
\end{tabular}

SUPPORTIVE CARE MAKES EXCELLENT

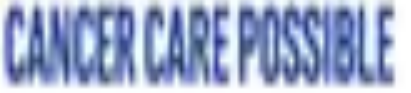

Table 1: Onset time and severity of pain of Oral mucositis among four subgroups.

Figure 1: Severity of mucositis and smokeless tobacco

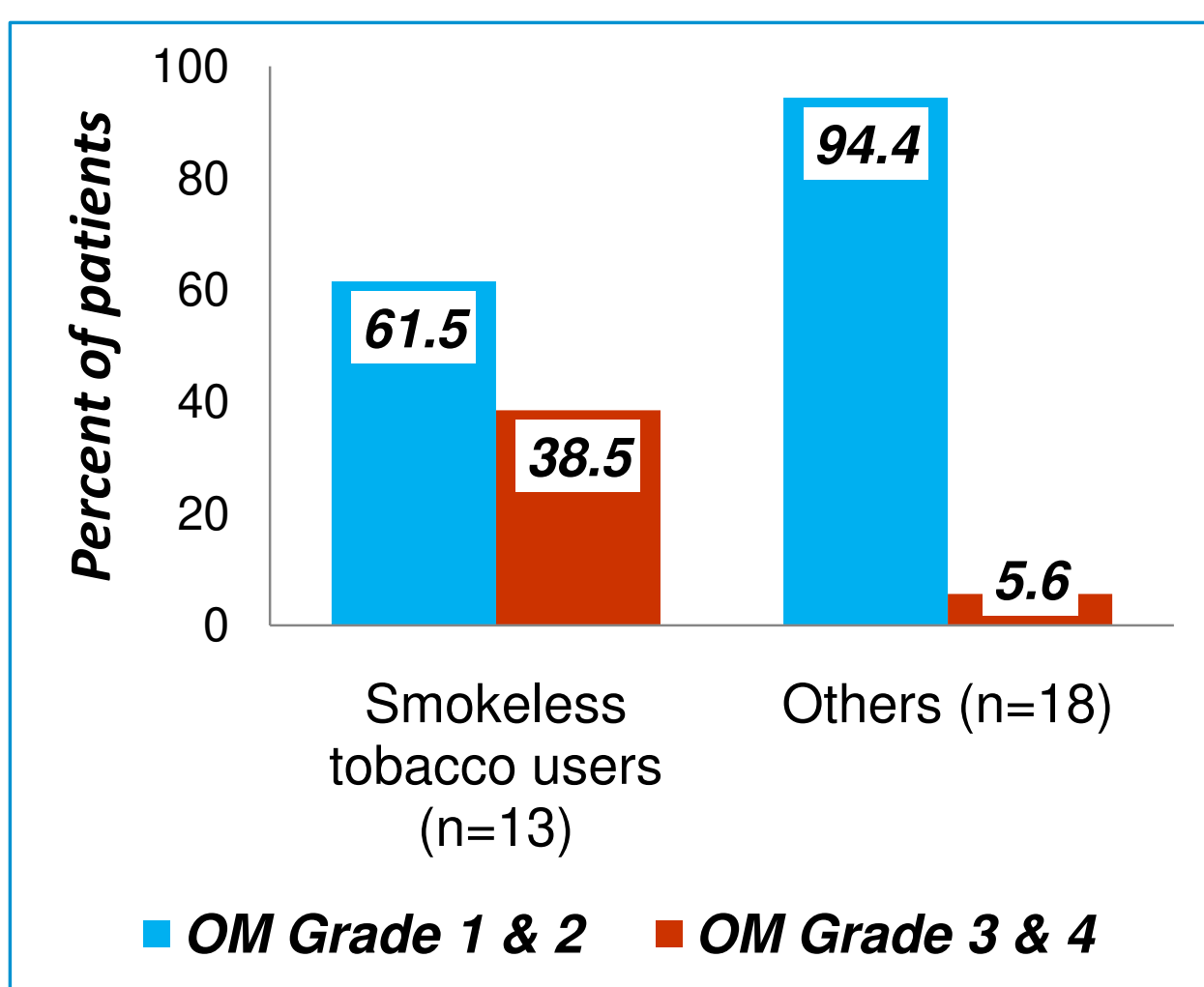

\section{Conclusion:}

The present study suggests that smokeless tobacco is associated with

- faster onset and

- higher grades of mucositis compared to smokers or tobacco non-users but associated with less severe pain.

However, future longitudinal study in larger population is recommended before fetching a definite conclusion.

\section{Conflict of interest: \\ $\mathrm{Nil}$ \\ Acknowledgement:}

All members of the Department of Radiation Oncology, Burdwan Medical College

\section{Contact:}

\section{Dr. Sandip Mukhopadhyay}

Dept. of Pharmacology, Burdwan Medical College, Burdwan, India

PIN: 713104. Email: sandipcmcl@gmail.com 